\title{
Detection of Micro-cracks in Metal Elements by Laser Excited Thermography
}

\author{
by W. Swiderski* \\ *Military Institute of Armament Technology, Wysznskiego 7 Str., 05-220 Zielonka, Poland,
} waldemar.swiderski@wp.pl

\begin{abstract}
Methods for the active infrared thermography require thermal excitation of tested object. The most popular is the use of optical heat sources: various types of heating lamps, lasers. The heat generated by laser heats the test surface with asymmetrical distribution beam [1]. In the structure of the material in which there are no defects, the heat flow from the heated surface should be also symmetrical. Disturbances in this flow symmetry testify to inhomogeneities (defects) in the internal structure of the tested material. For non-destructive testing of metal elements with micro-cracks, infrared thermography with laser thermal stimulation was used and both computer numerical simulations (using the ThermoCalc program) and experimental testing were carried out. In the experimental tests, a semiconductor laser with a wavelength of $808 \mathrm{~nm}$ and maximum power of $32 \mathrm{~W}$ was used for thermal stimulation. Changes of temperature field on the surface of the test sample were recorded with a thermal camera, FLIR 7600 SC. Pulse phase thermography method was used and selected results, together with their analysis, are presented in this paper.
\end{abstract}

\section{Introduction}

Each inhomogeneity of a structure causes changes in mechanical properties, but also affects other parameters, e.g. thermal conductivity. This results in a change in the distribution of the temperature field on the surface of the test material in order to detect a defect by using the thermal camera. Possibilities of infrared thermography for detecting microcracks in the metal element are shown in the example of microcracks on the surface of the valve head in the internal combustion engine. The operating conditions in which the combustion engine valve operates are severe due to mechanical and thermal loads. The valve head is loaded with static and dynamic forces.

During use, the valves in an internal combustion engine are subject to wear and damage which impairs the quality of their functioning. Valves are functional units necessary for the implementation of engine operating processes; the quality of the device's functioning depends on the quality of valve operation. Maintaining and increasing the quality of valve operation is reduced to detecting or identifying damage to valve components and eliminating these damages by repairing or replacing damaged components. In practice, identification of valve damage is difficult due to the lack of appropriate identification methodology. This lack results mainly from the large variety of valve construction solutions and the various areas of applications and loads. Figure 1 shows the forces acting on a valve during engine operation [2].

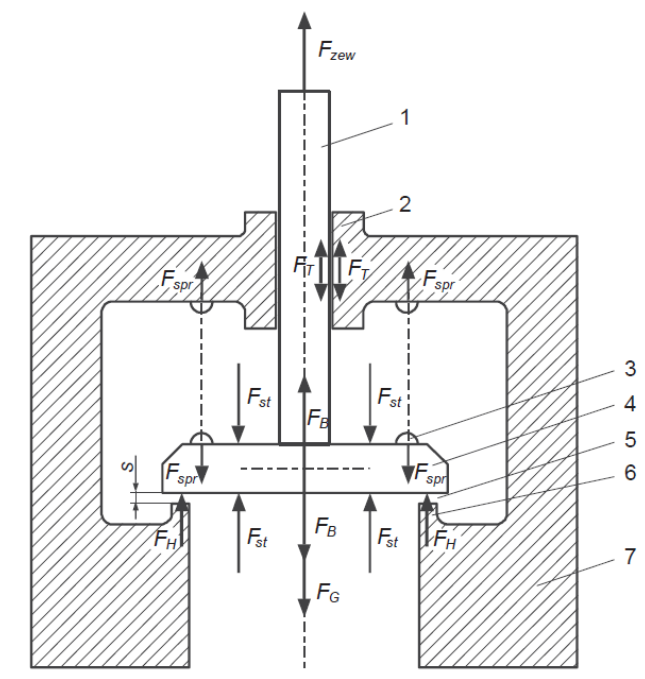

Fig. 1: The forces acting on the valve components: $F_{z e w}$ - external force acting on movable elements, $F_{\text {spr }}-$ restoring force of a spring, $F_{T}-$ friction force between the valve stem and guide, $F_{B}$ - inertial force of moving elements, $F_{H}-$ hydrodynamic force in the gap, $F_{s t}$ - force of the stream of liquid, $F_{G}$ - earth pull, Smax - valve lift; 1 - stem, 2 guide, 3 - spring, 4 - valve head, 5 - plate - valve seat gap, 6 - valve seat, 7 - valve housing [2] 
During valve operation, the following forces operate on the closing element:

- the force of jet working fluid $\left(F_{s t}\right)$ - can be calculated by numerical methods from the flow equation;

- $\quad$ the inertial force of the movable element $F_{B}[3]$ :

$$
F_{B}=\left(m_{V}+{ }^{w}{ }_{S} / 3\right)\left(-a_{V}\right)
$$

where:

$\mathrm{m}_{\mathrm{v}}$ - mass of the movable valve element;

$\mathrm{ms}_{\mathrm{s}}$ - spring mass (takes into account $1 / 3$ of the spring weight here);

av - acceleration of the closing element / movable valve.

- the elasticity force of the spring $F_{s p r}$ is proportional to the lift of the closing element of the $h_{v}$ valve:

$$
F_{\text {gpy }}=F_{\text {gpro }}+C_{\text {spy }} h_{V}
$$

where:

$F_{\text {spro }}$ - tension bearing of the spring (force with which the movable element is pressed against the valve seat);

$\mathrm{C}_{\text {spr }}$ - spring constant.

- the force of gravity of the movable element $F_{G}[3]$ is approximately constant because the density of the surrounding fluid changes slightly (very little);

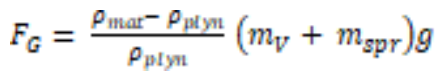

- the friction force of the guide elements $\mathrm{F}_{\mathrm{T}}$;

- the external force which forces the movement of the valve $F_{z e w .}$

The resultant forces acting on the movable element of the valve determine the movement of the closing element. Microcracks are the initial phase of damage, the next stage may be breaking of the head and subsequent damaging of the engine. Valve damage is the result of a collective of loads acting during use on the valve components.

Damage to the valve elements causes a change in the course and values of forces acting on the valve elements, changes in the mechanical properties of the material of the elements, and a leak in the valve. microcracks.

A thermography method with laser thermal stimulation was used for non-destructive testing to detect

\section{Numerical modeling}

In order to determine the possibility of detecting microcracks using thermography with laser stimulation, a model with dimensions $30 \times 30 \times 3 \mathrm{~mm}$ was made from steel in which there were microcracks with a length of $10 \mathrm{~mm}$, width 0.05 $\mathrm{mm}$, and depth $2 \mathrm{~mm}$ (Fig. 2). This model was tested using ThermoCalc- $6 \mathrm{~L}^{\mathrm{TM}}$ software [4]. ThermoCalc ${ }^{\mathrm{TM}}-6 \mathrm{~L}$ offers the solution to a 3D Cartesian-coordinate transient heat conduction problem for a parallelepiped-shaped body that may contain up parallelepiped-shaped defects. The body is heated or cooled down on the front surface with an external 'heat' pulse. The front-surface heat flux is assumed to be uniform or Gaussian-distributed in space. The heat flux center can be located at any point on a front surface. Along with the external thermal stimulation on the front surface, both the front and rear surface are cooled down according to Newton's law.

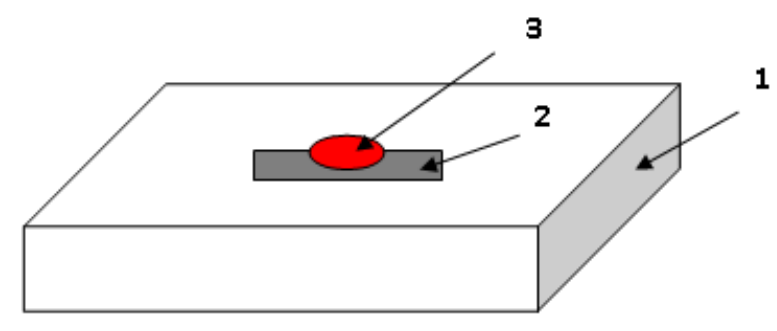

Fig. 2: Model of testing sample: 1 - sample, 2 - microcrack, 3 - heating area.

The thermal parameters of steel and the air filling the microcracks are given in Table 1. During the modeling of thermal processes occurring on the surface of the sample model, the surface was heated by a pulsed heat stream with a density of $1.2 \mathrm{~kW} / \mathrm{m}^{2}$. The stream was stimulated by heating with a $5 \mathrm{~mm}$ diameter laser beam. The center of the stream was directed to the microcracks. Table 2 presents the selected results of the temperature difference on the surface between the micro-cracking and the outside during the heating and cooling phase of the sample. 
Table 1. Thermal properties of materials used in model

\begin{tabular}{|l|c|c|c|}
\hline \multicolumn{1}{|c|}{ Material } & \multicolumn{1}{c|}{$\begin{array}{c}\text { Density, } \\
\mathrm{kg} / \mathrm{m}^{3}\end{array}$} & $\begin{array}{c}\text { Specific Heat, } \\
\mathrm{J} /(\mathrm{kg} \cdot \mathrm{K})\end{array}$ & $\begin{array}{c}\text { Conductivity, } \\
\mathrm{W} /(\mathrm{m} \cdot \mathrm{K})\end{array}$ \\
\hline Air (thin gaps) & 1.2 & 1005 & 0.07 \\
\hline Steel & 8240 & 468 & 13.4 \\
\hline
\end{tabular}

Table 2. Selected results of numerical calculations

\begin{tabular}{|l|c|c|c|}
\hline Time, $\mathrm{s}$ & 0.26 & 3.12 & 5.0 \\
\hline$\Delta \mathrm{T},{ }^{\circ} \mathrm{C}$ & 0.91 & 0.1 & -0.82 \\
\hline
\end{tabular}

\section{Experimental set-up}

In Figure 3., a photograph of an internal combustion engine valve is shown. A test was also performed using a microscope with a magnification of $40 \mathrm{x}$ image microcracks. This is shown in Figure 4, on which the microcracks are clearly visible perpendicular to the surface of the valve head from the side of its working surface. Micro-cracking is also visible on the side of the valve head, as shown in Figure 5.

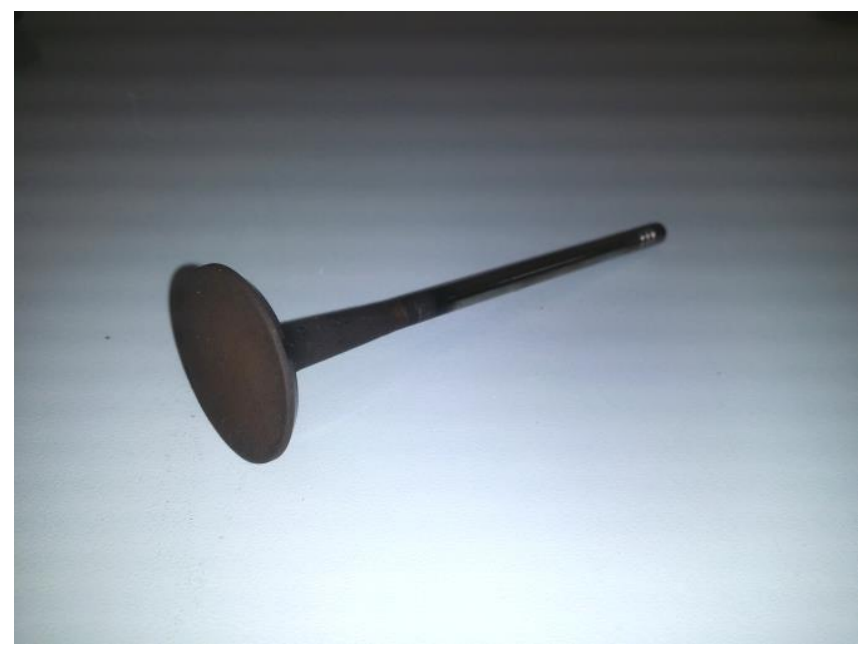

Fig. 3: Photograph of the valve

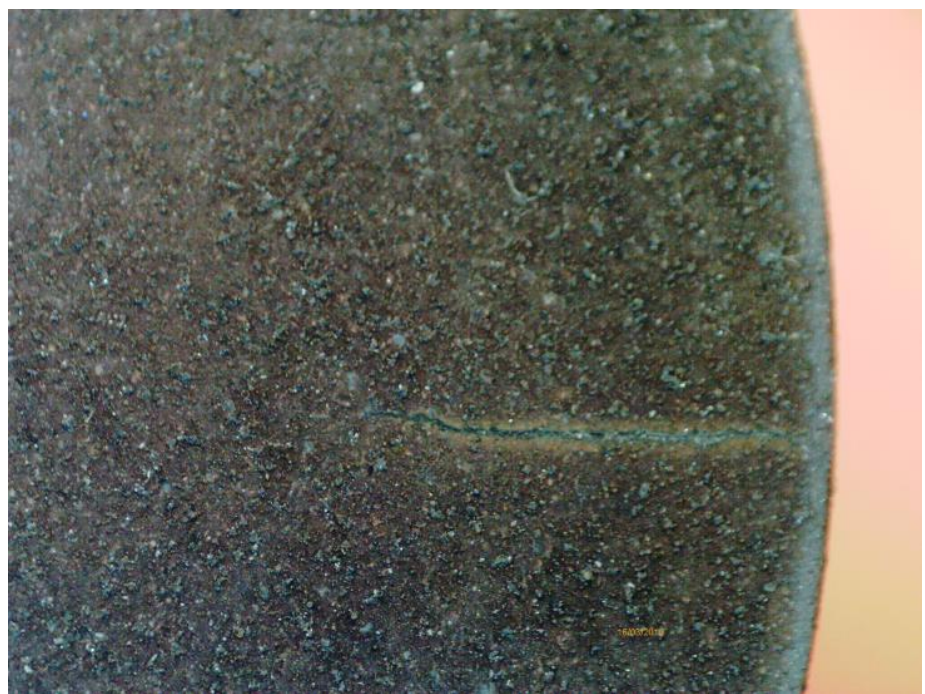

Fig. 4: Photograph of a valve head with visible microcracking - magnification 40x 


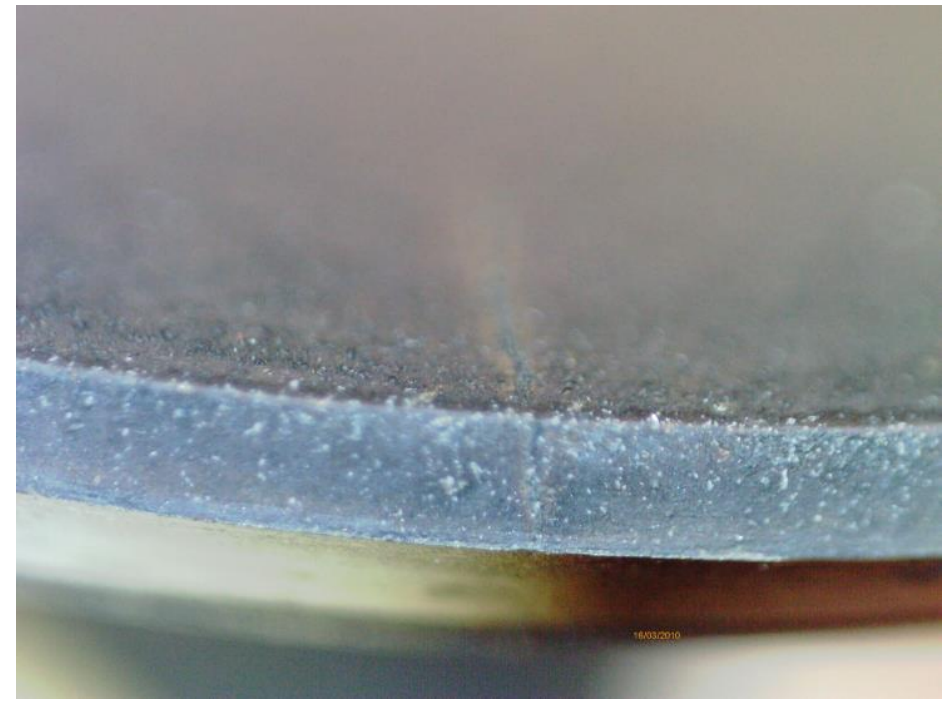

Fig. 5: Photo taken at the side of the valve head with visible microcracking - magnification 40x chamber.

Fig. 6 presents the measurement stand. Due to laser radiation, the measurement was made in a sealed

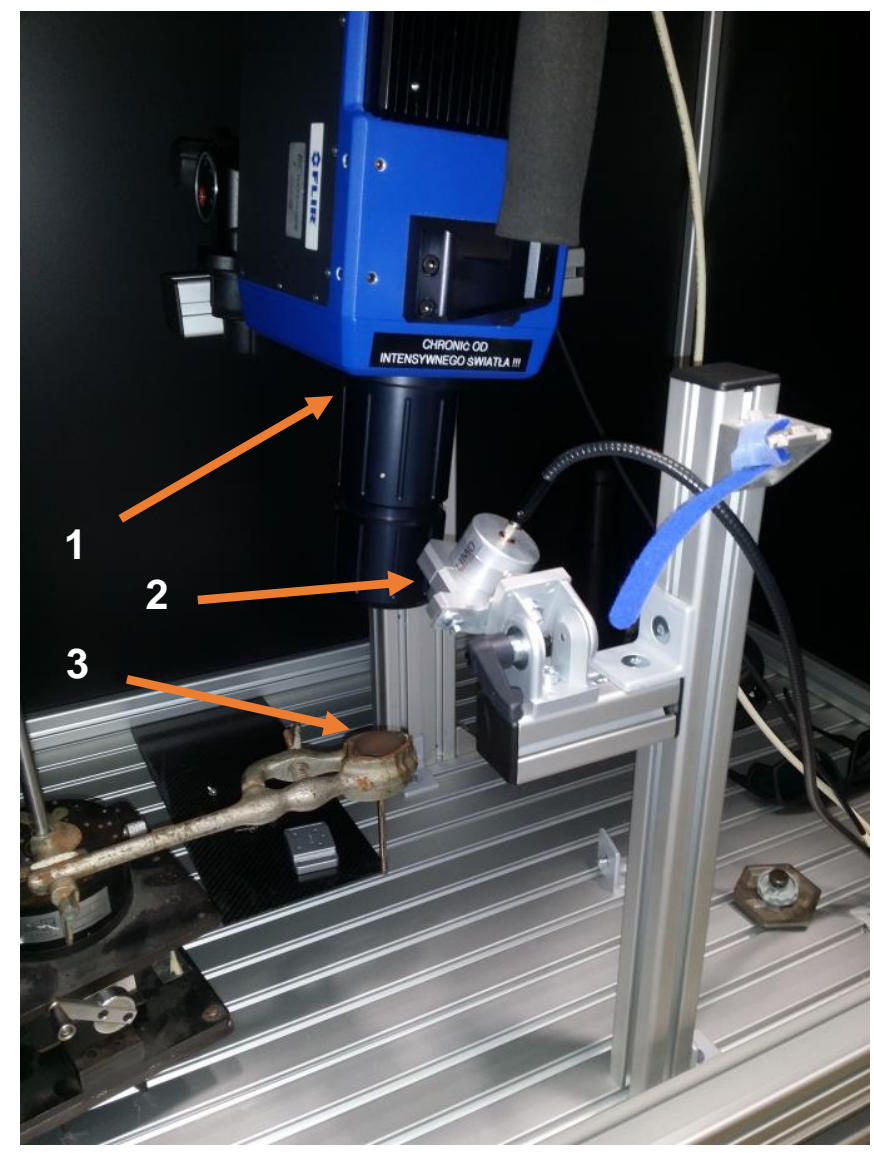

Fig. 6: Set up: 1- thermal camera, 2 - laser, 3 - valve.

In the experimental tests, a semiconductor laser with a wavelength of $808 \mathrm{~nm}$ and a maximum power of $32 \mathrm{~W}$ was used for thermal stimulation. Changes of temperature field on the surface of the test sample were recorded with a thermal camera, FLIR 7600 SC, with a microscopic lens. The surface of the tested valve taken from a car engine was 
pulsed with a laser for 2 seconds, the diameter of the laser beam incident on the tested surface was $5 \mathrm{~mm}$. The time of recording of the changes in the temperature field caused by heating with a laser beam was 5 seconds.

\section{Results}

Fig.7 shows a source thermogram made perpendicular to the working surface of the valve head with visible microcrack, the shape and dimensions of which confirm the photograph taken under the microscope with clearly visible microcracking. The microcrack on the side of the valve head is shown in the thermogram in Fig.8. It is also clearly visible.

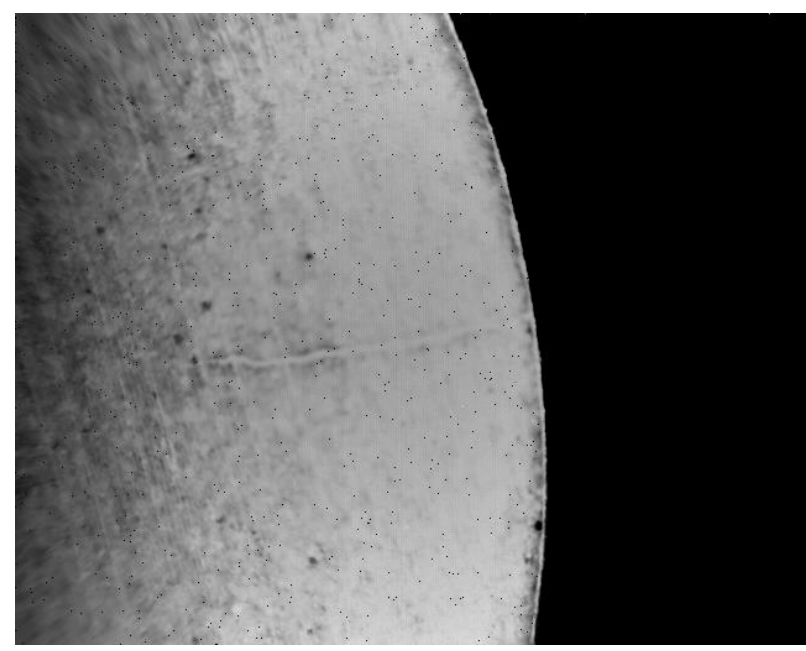

Fig. 7: The best source thermogram of a valve head microcrack made perpendicular to its working surface

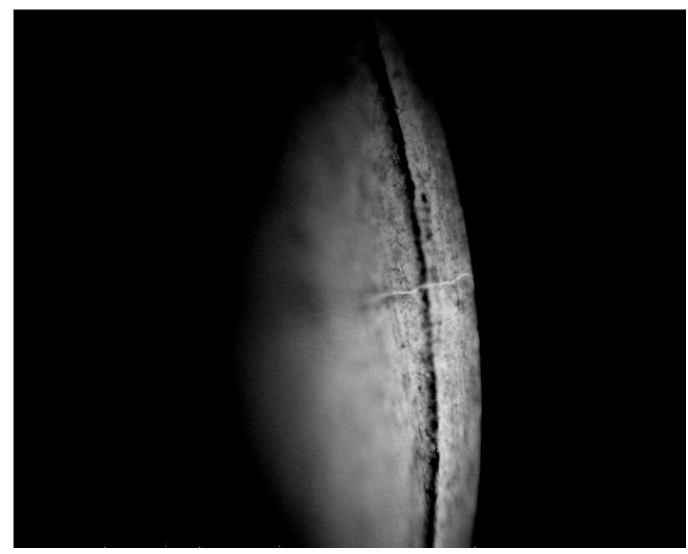

Fig. 8: The best source thermogram of a microcrack made on the side of the valve head

Fig. 9 shows the profiles of temperature changes over selected characteristic times, such as the results of numerical calculations presented in Table 1, on the surface of the valve head. As the experimental course of changes shows, the temperature differences over the microcracks ( 46 pixel in the graphs) coincide with the results of numerical calculations.

Figures 10 and 11 present the results obtained as a result of the analysis of phase and amplitude changes recorded during the test. The phase image of the microcrack is better visible than on the best source thermogram. Also visible when comparing figures 7 and 9. The amplitude image does not improve the microcracks image; however, there are visible irregularities on the surface of the valve head (Fig.11), which can also be seen in the microscope image (Fig. $4)$. 


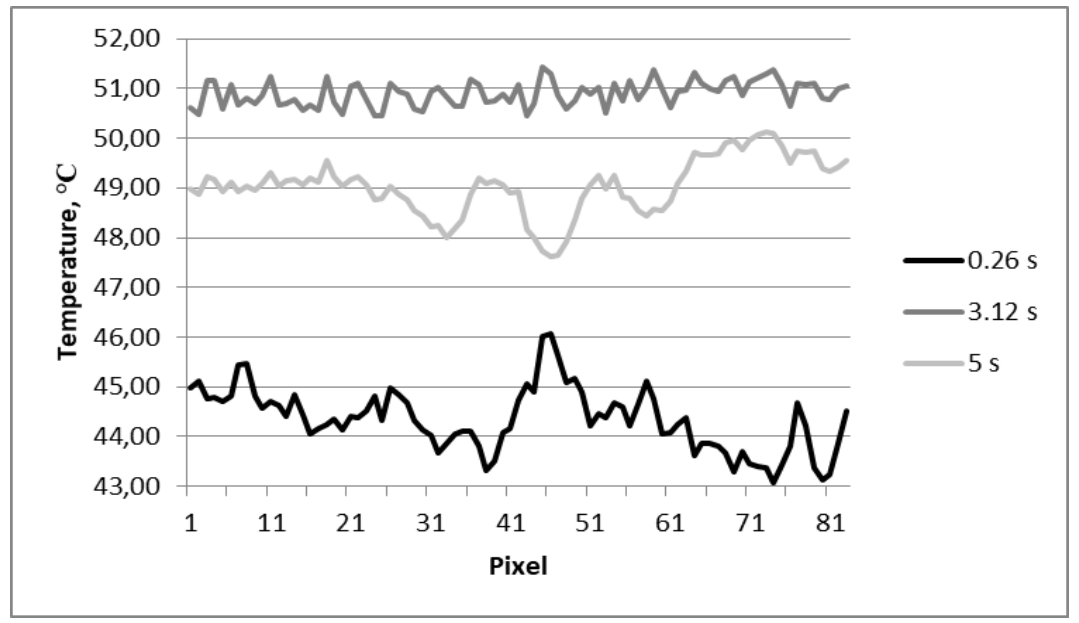

Fig. 9: Courses of temperature changes on the test surface of the valve.

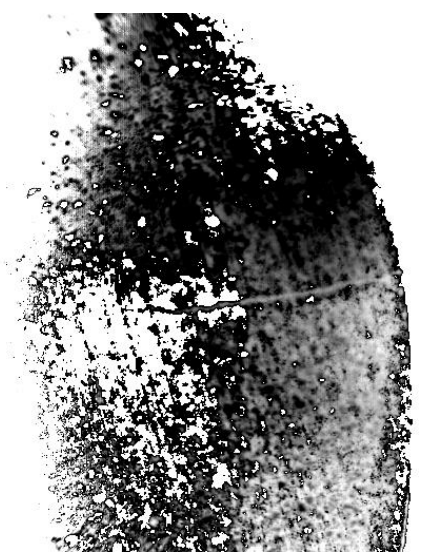

Fig. 10: Phase image of microcrack

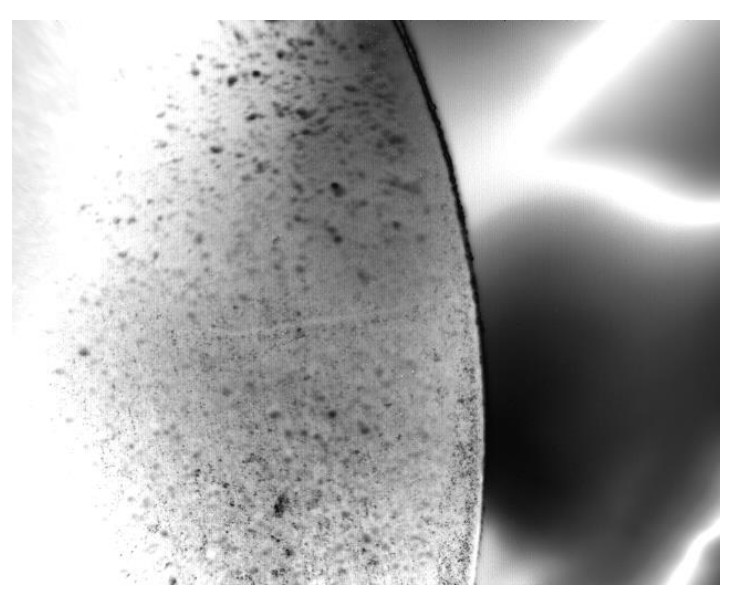

Fig. 11: Amplitude image of microcrack

\section{Summery}

Experimental tests have shown that the method used is effective in detecting microcracks in metal elements. The use of a microscopic lens in a thermal camera allows both the detection of microcracks as well as precise identification of changes occurring on the surface under experimental test conditions. 
In further work, we intend to conduct tests to detect micro-defects in other materials using laser heating and a microscope lens for a thermal camera.

\section{REFERENCES}

[1] Swiderski W. Non-destructive testing of CFRP by laser excited thermography, Composite Structures, 2019; 209: 710-714.

[2] Bielawski. P. Problems of reciprocating machine valve diagnostics, Pomiary automatyka Robotyka , 2013, No 12, pp.82-89 (in Polish).

[3] Schlücker E., Blendinger S., Schade O. Verschleißdurch Kavitation in Ventilspalt fluidgesteuerter Ventile, Tribologie + Schmierungstechnik, 2008, Vol. 55, pp. 28-31 (in Germany).

[4] ThermoCalc-6L ${ }^{\mathrm{TM}}$, Operation Manual, Innovation Ltd., Tomsk, 2014. 